\title{
Solubility of Nitrogen in Liquid Chromium and Chromium-Iron Alloys*
}

\author{
By Fujio ISHII,** Yasutaka IGUCHI** and Shiro BAN-YA**
}

\section{Synopsis}

The solubility of nitrogen in liquid chromium and chromium-iron alloys has been studied by a sampling method at the temperatures of $1550 \sim$ $1780^{\circ} \mathrm{C}$ and under $0.04 \sim 1.0$ atm of nitrogen.

The equilibrium constant of the solution reaction and the activity of nitrogen in liquid chromium and chromium-iron alloys were determined by applying the interstitial model to the experimental results.

The results obtained are summarized as follows:

(1) Nitrogen dissolved in liquid chromium and chromium-iron alloys up to $50 \%$ Fe does not obey the Sieverts' law, and the solubility of nitrogen in liquid chromium is given by the following equation.

$$
\begin{aligned}
& \log K(Z)=5515 / T-3.19_{3}, \\
& K(Z)=a_{\mathrm{N}} / \sqrt{P_{\mathrm{N}_{2}}}=\phi_{\mathrm{N}} Z_{\mathrm{N}} / \sqrt{P_{\mathrm{N}_{2}}}
\end{aligned}
$$

(2) The activity coefficients of nitrogen based on pure liquid chromium are expressed as follows:

$$
\begin{aligned}
& \log \phi_{\mathrm{N}(\mathrm{Cr})}^{\mathrm{N}}=\left(4235 / T-1.51_{3}\right) \cdot Y_{N} \quad Y_{N}<0.21 \\
& \log \phi_{\mathrm{N}(\mathrm{Cr})}^{\mathrm{Fe}}=1.80 \cdot Y_{\mathrm{Fe}} \quad Y_{\mathrm{Fe}}<0.7
\end{aligned}
$$

(3) The activity coefficients of nitrogen in liquid iron-chromium alloys based on pure liquid iron are shown by the following equations:

$$
\begin{array}{ll}
\log \gamma_{\mathrm{N}(\mathrm{Fe})}^{\mathrm{Cr}}=(-13765 / T+3.10) \cdot X_{\mathrm{Cr}} & X_{\mathrm{Cr}}<0.16 \\
\log f_{\mathrm{N}(\mathrm{Fe})}^{\mathrm{Cr}}=(-148 / T \times 0.033) \cdot[\% \mathrm{Cr}] & {[\% \mathrm{Cr}]<15}
\end{array}
$$

where, $Y_{\mathrm{N}}, Z_{\mathrm{N}}$ : the mole ratio and the lattice ratio of nitrogen in the liquid metal, respectively.

\section{Introduction}

The metallic chromium of commercial grade is unable to be used as practical industrial materials due to the brittleness and hardness, but highly refined chromium has fairly good forgeability and machinability. It is well known that the discrepancy of these mechanical properties is caused by the contamination of non-metallic elements such as nitrogen, oxygen, sulphur and carbon. Especially, nitrogen dissolved in chromium has a great effect on these properties.

Therefore, the attention hss been directed to the solubility of nitrogen in liquid chromium by several investigators. ${ }^{1-3)}$ In some of the previous works, the nitrogen solubility of liquid chromium has been studied by the levitation melting method at nearly $2000{ }^{\circ} \mathrm{C}$ and under one atmospheric pressure of nitrogen. These results showed that the liquid chromium in contact with one atmospheric pressure of nitrogen did not form the nitrides, and that its solubility did not obey the Sieverts' law.

However, for the better understanding of the physico-chemical behaviour of nitrogen in liquid chromium, it is necessary to have reliable data concerning the solubility of nitrogen and the kinetics of absorption and desorption in liquid chromium and chromium-iron alloys. To extend our knowledge in these areas, the solubility of nitrogen in liquid chromium and chromium alloys has been studied by a sampling method at the temperatures from 1550 to $1780{ }^{\circ} \mathrm{C}$ and under $0.04 \sim 1.0$ atm of nitrogen. Since nitrogen seems one of the interstitial elements in liquid chromium and chromium alloys, the results obtained have been treated by the interstitial model proposed by J. Chipman. ${ }^{4}$ )

\section{Experimental Procedures}

The experimental apparatus and procedure were essentially the same as that described previously for the measurements of nitrogen solubility in iron alloys. ${ }^{5)}$

\section{Apparatus}

The apparatus consisted of a high frequency induction furnace (20 KVA), a reaction tube, purification trains, gas flow meters, and a gas chromatograph. Figure 1 shows the inner arrangement of the furnace. The quartz reaction tube $(60 \mathrm{~mm}$ O.D., $52 \mathrm{~mm}$ I.D. by $500 \mathrm{~mm}$ long) was fitted with watercooled brass endcaps, on the upper one of which the gas inlet tube was provided for sighting a pyrometer down. The melt temperatures were measured with

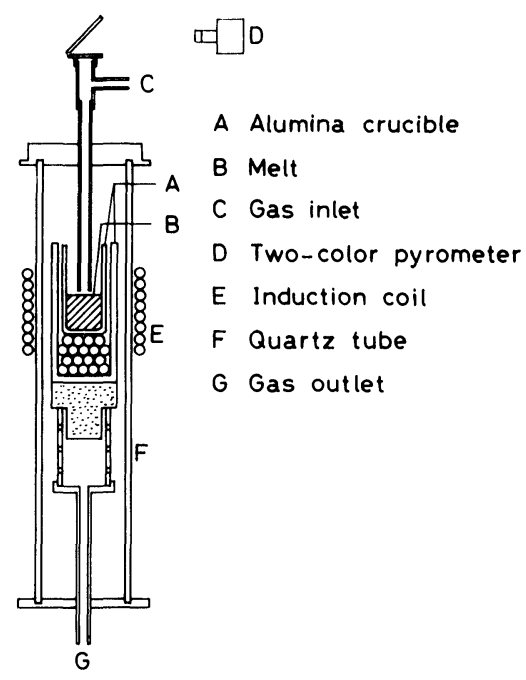

Fig. 1. Furnace cross section.

* Originally published in Tetsu-to-Hagané, 69 (1983), 913, in Japanese. English version received on May 16, 1985; accepted in the final form on September 13, 1985. (C) 1986 ISIJ

** Department of Metallurgy, Faculty of Engineering, Tohoku University, Aza Aoba, Aramaki, Sendai 980. 
a two-color pyrometer which was calibrated periodically with the melting points of pure iron and nickel under the experimental conditions.

\section{Materials}

Pure chromium of $99.99 \%$ purity and electrolytic iron were used in the experiments. These materials were inductively melted in a recrystallized alumina crucible (SSA-S) and further purified in one atmosphere of $\mathrm{H}_{2}$. Chromium-iron alloys were prepared from the purified metals, and the composition of these alloys was determined by chemical analysis. The charge for a run was about $100 \mathrm{~g}$ of these metals held in a pure alumina crucible ( $25 \mathrm{~mm}$ I.D., SSA-S). An outer alumina crucible (38 mm I.D., CP) was also used as a safety protection. Since the reaction tube was equipped with the purification trains for nitrogen, argon and hydrogen, the nitrogen pressure $\left(P_{\mathrm{N}_{2}}\right)$ could be varied from 0.04 to 0.1 atm by using argon. The nitrogen pressure in the atmosphere was determined by gas chromatography using the standard gas in the cylinder.

\section{Procedure}

At the beginning of each run, hydrogen was supplied to the reaction tube after the evacuation of the reaction tube. The charges were then melted by induction heating. The range of the experimental temperatures was from 1550 to $1780{ }^{\circ} \mathrm{C}$. After the melts were kept for about $2 \mathrm{hr}$ under one atmosphere of hydrogen, the nitrogen or nitrogen-argon gas mixture was introduced into the reaction tube, and the equilibrium between the melts and these gases was attained. For the measurement under the nitrogen pressure below $1 \mathrm{~atm}$, the melts were first held at the experimental temperature for $2 \mathrm{hr}$ under nitrogen or hydrogen of 1 atm, and then the gas mixture of the appropriate ratio was introduced in order to assure the approach to the equilibrium from both the sides. After the equilibration, a $5 \mathrm{~g}$ sample was taken from the bath by using a $3 \mathrm{~mm}$ dia. quartz tube and quenched into water. It was confirmed that the equilibrium was attained after about $2 \mathrm{hr}$ under one atmosphere of nitrogen. Experiments were generally continued for periods of time ranging from 3 to $4 \mathrm{hr}$. Nitrogen in metals was determined by the micro-Kjeldahl method.

\section{Experimental Results and Discussion}

Since nitrides have not been found in liquid chromium and chromium-iron alloys under one atmosphere of nitrogen, nitrogen dissolution in liquid metals is generally represented by the following reaction.

$$
1 / 2 \mathrm{~N}_{2}=\underline{\mathrm{N}} \quad \text { (in liquid metals) }
$$

for which the equilibrium constant $K$ is given by

$$
K=a_{\mathrm{N}} / \sqrt{P_{\mathrm{N}_{2}}}
$$

By applying the interstitial model, ${ }^{4,6)}$ the atom ratio
$Y_{\mathrm{N}}$ and the lattice ratio $Z_{\mathrm{N}}$ as the concentration of components in liquid metals are defined as follows:

$$
\begin{aligned}
& Z_{\mathrm{N}}=n_{\mathrm{N}} /\left(n_{\mathrm{Cr}}+n_{\mathrm{Fe}}-n_{\mathrm{N}}\right)=X_{\mathrm{N}} /\left(1-2 X_{\mathrm{N}}\right) \\
& Y_{\mathrm{N}}=n_{\mathrm{N}} /\left(n_{\mathrm{Cr}}+n_{\mathrm{Fe}}\right)=X_{\mathrm{N}} /\left(1-X_{\mathrm{N}}\right) \ldots \ldots \ldots \ldots \\
& Y_{\mathrm{Fe}}=n_{\mathrm{Fe}} /\left(n_{\mathrm{Cr}}+n_{\mathrm{Fe}}\right)=X_{\mathrm{Fe}} /\left(1-X_{\mathrm{N}}\right) \ldots \ldots
\end{aligned}
$$

where, $n_{i}, X_{i}$ : mole and mole fraction of component $i$, respectively.

As the reference state of the activity is taken to the infinitely dilute solution of nitrogen in liquid pure chromium, the activity coefficients $\psi_{\mathrm{N}(\mathrm{Cr})}$ and the interaction parameters $\theta_{i}$ in liquid metals are then given by

$$
\begin{aligned}
& a_{\mathrm{N}}=\phi_{\mathrm{N}(\mathrm{Cr})} \cdot Z_{\mathrm{N}}=\phi_{\mathrm{N}(\mathrm{Cr})}^{\mathrm{N}} \cdot \psi_{\mathrm{N}(\mathrm{Cr})}^{\mathrm{Fe}} \cdot Z_{\mathrm{N}} \\
& \theta_{\mathrm{N}(\mathrm{Cr})}^{\mathrm{N}}=\partial \ln \phi_{\mathrm{N}(\mathrm{Cr})} / \partial Y_{\mathrm{N}} \ldots \ldots \ldots \ldots \ldots \ldots \ldots \ldots \ldots \ldots \ldots \ldots \ldots \ldots \ldots \\
& \theta_{\mathrm{N}(\mathrm{Cr})}^{\mathrm{Fe}}=\partial \ln \phi_{\mathrm{N}(\mathrm{Cr})} / \partial Y_{\mathrm{Fe}} \ldots \ldots \ldots \ldots \ldots \ldots
\end{aligned}
$$

\section{Chromium System}

The solubility of nitrogen in liquid chromium was measured at the temperatures from 1700 to $1780{ }^{\circ} \mathrm{C}$. The results obtained at the various nitrogen pressures are shown in Fig. 2. It was observed that the solubility of nitrogen in liquid chromium did not obey the Sieverts' law, and decreased with the increasing temperature. This confirms the results obtained by Humbert and Elliott, ${ }^{1)}$ and Tsu, Saito and Sakuma. ${ }^{2)}$

Since the lattice ratio $Z_{\mathrm{N}}$ is employed as the concentration variable of nitrogen in metal in the interstitial model, the apparent and true equilibrium constants of Eq. (1) are defined with $K^{\prime}(Z)\left(=Z_{\mathrm{N}} / \sqrt{P_{\mathrm{N}_{2}}}\right)$ and $K(Z)\left(=a_{\mathrm{N}} / \sqrt{P_{\mathrm{N}_{2}}}\right)$, respectively. Therefore, the following equation is given by the combination of Eqs. (2) to (7).

$$
\begin{gathered}
\log K^{\prime}(Z)=\log K(Z)-\log \phi_{\mathrm{N}(\mathrm{Cr})}^{\mathrm{N}}=\log K(Z) \\
\left.-\theta_{\mathrm{N}(\mathrm{Cr})}^{\mathrm{N}} / 2.303\right) \cdot Y_{\mathrm{N}} \ldots \ldots \ldots \ldots \ldots \ldots \ldots \ldots \ldots \ldots \ldots \ldots \ldots \ldots \ldots \ldots
\end{gathered}
$$

Namely, the observed values of $\log K^{\prime}(Z)$ should be a linear function of the atom ratio $Y_{\mathrm{N}}$ if the model

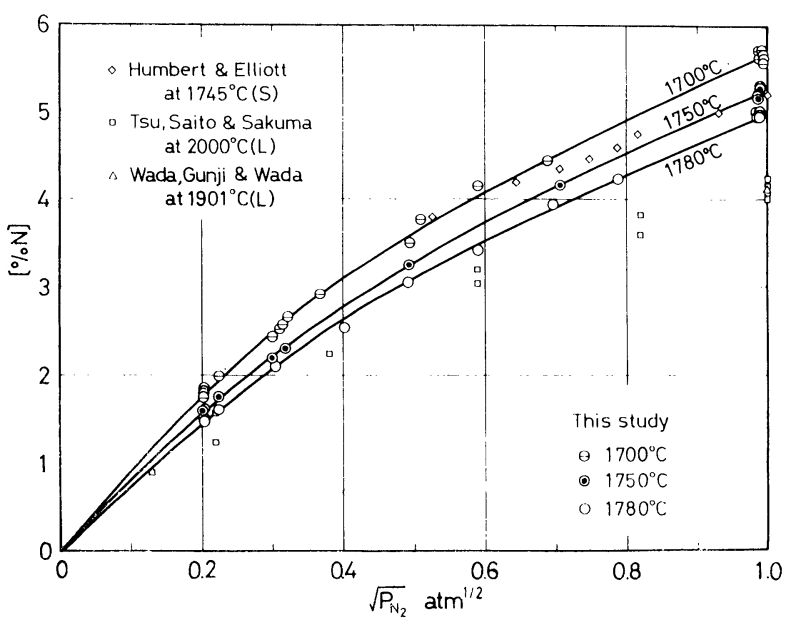

(S): Sieverts' method (L): Levitation melting

Fig. 2. Solubility of nitrogen in liquid chromium. 
was satisfied in the experimental range. The limiting value of $\log K^{\prime}(Z)$ at zero atom ratio of nitrogen is designated by $\log K(Z)$, and the slope of the line at each temperature gives the interaction parameter $\left(\theta_{\mathrm{N}}^{\mathrm{N}}(\mathrm{Cr}) / 2.303\right)$. The results obtained in Fig. 2 were rearranged in Fig. 3 according to Eq. (9). The observed values of $\log K^{\prime}(Z)$ at each experimental temperature were expressed by the following equations (10) to (12) within the standard deviation of $\sigma= \pm 0.009$.

$$
\begin{aligned}
& \log K^{\prime}(Z)=-0.398-0.634 Y_{\mathrm{N}} \\
& 1700^{\circ} \mathrm{C} \quad Y_{\mathrm{N}}<0.225 \\
& \log K^{\prime}(Z)=-0.467-0.580 Y_{\mathrm{N}} \\
& 1750^{\circ} \mathrm{C} \quad Y_{\mathrm{N}}<0.21 \\
& \log K^{\prime}(Z)=-0.507-0.550 Y_{\mathrm{N}} \\
& 1780^{\circ} \mathrm{C} \quad Y_{\mathrm{N}}<0.20
\end{aligned}
$$

In Fig. 3, the previous results at $1745^{\circ} \mathrm{C}$ by Humbert and Elliott were in good agreement with the present results at $1750{ }^{\circ} \mathrm{C}$, but their experimental range of nitrogen content was too narrow to determine the accurate slope of the line. The measurements of Tsu et al. by the levitation melting method were rather scattered, and the slope was determined by the least squares method. Wada et al. also applied the levitation melting method under one atmosphere of nitrogen, and assumed the Henry's law in the experimental range.

The following equations (13) and (14) were obtained as the equilibrium constant of nitrogen dissolution into liquid chromium from the first term of the right hand side in Eqs. (10) to (12).

$$
\begin{aligned}
& \log K(Z)=\log K(X)=5515 / T-3.19_{3} \\
& \log K(\%)=5515 / \mathcal{T}-1.76_{3} \quad \ldots \ldots \ldots \ldots \ldots
\end{aligned}
$$

where the equation of $\log K(\%)$ was converted from that of $\log K(Z)$. The comparison of $\log K(Z)$ is shown in Fig. 4, in which there are two kinds of data for the results by $\mathrm{Tsu}$ et al. The observed line represents the direct data of the measurement, and the points corrected are the results by some corrections

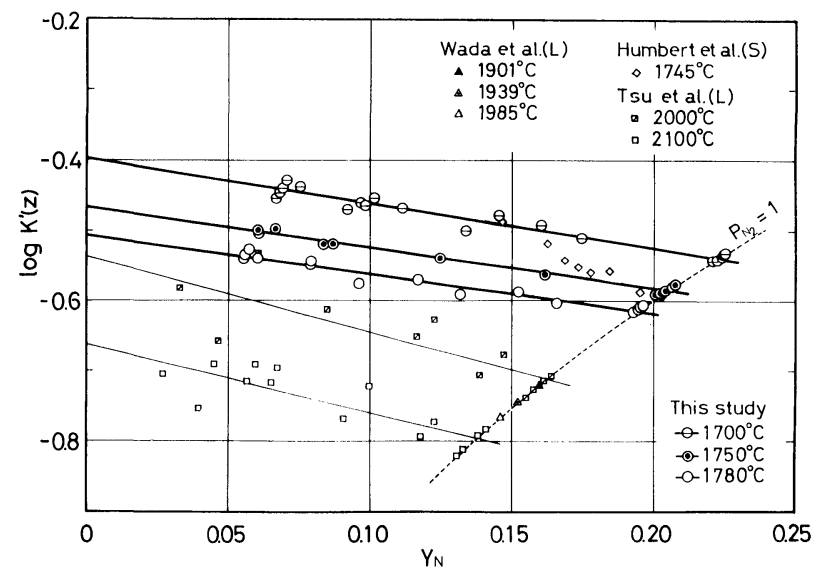

Fig. 3. Relation between apparent equilibrium constant $\log K^{\prime}(Z)$ and the concentration of nitrogen in liquid chromium. for the effect of chromium vapor at the high temperatures of the levitation melting.

The activity coefficient of nitrogen, $\log \phi_{\mathrm{N}(\mathrm{Cr})}^{\mathrm{N}}$, was plotted against $Y_{\mathrm{N}}$ in Fig. 5. The interaction parameters $\theta_{\mathrm{N}(\mathrm{Cr})}^{\mathrm{N}} / 2.303$ were represented by the following equations.

$$
\begin{aligned}
& \theta_{\mathrm{N}(\mathrm{Cr})}^{\mathrm{N}} / 2.303=\partial \log \psi_{\mathrm{N}(\mathrm{Cr})} / \partial Y_{\mathrm{N}}=4235 / T-1.51_{3} \\
& \varepsilon_{\mathrm{N}(\mathrm{Cr})}^{\mathrm{N}} / 2.303=\partial \log \gamma_{\mathrm{N}} / \partial X_{\mathrm{N}}=4235 / T-0.64_{5} \\
& e_{\mathrm{N}(\mathrm{Cr})}^{\mathrm{N}}=\partial \log f_{\mathrm{N}(\mathrm{Cr})} / \partial[\%]=157 / T-0.035_{7}
\end{aligned}
$$

At 1 atm of nitrogen, the solubility of nitrogen in liquid chromium is shown in Fig. 6 and expressed by

$$
\begin{aligned}
& \log \left[Z_{\mathrm{N}}\right]_{P_{\mathrm{N}_{2}=1}}=3612 / T-2.37_{4} \\
& \log [\% \mathrm{~N}]_{P_{\mathrm{N}_{2}=1}}=2868 / T-0.69_{8}
\end{aligned}
$$

The extrapolation of the present results to the higher temperature range shows the good agreement with all of the earlier results. ${ }^{1-3)}$

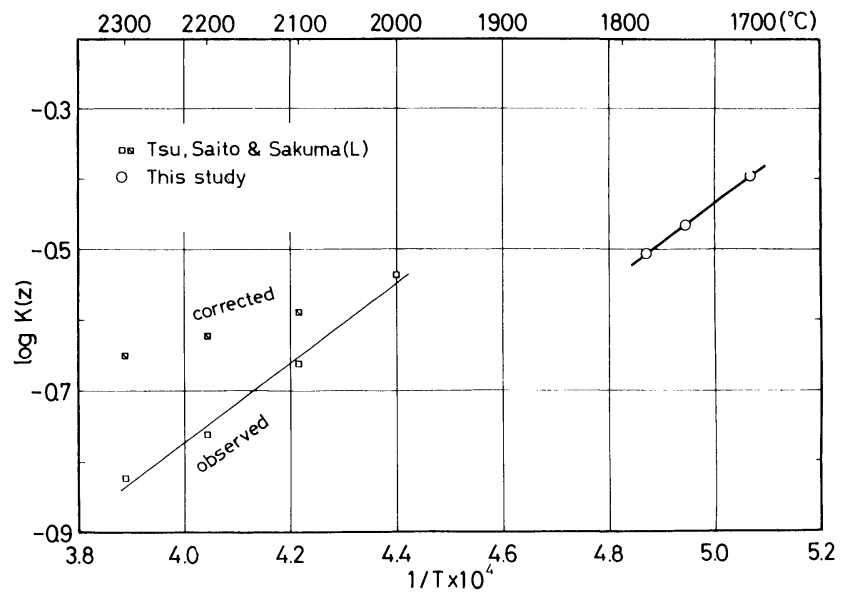

Fig. 4. Temperature dependence of $\log K(Z)$.

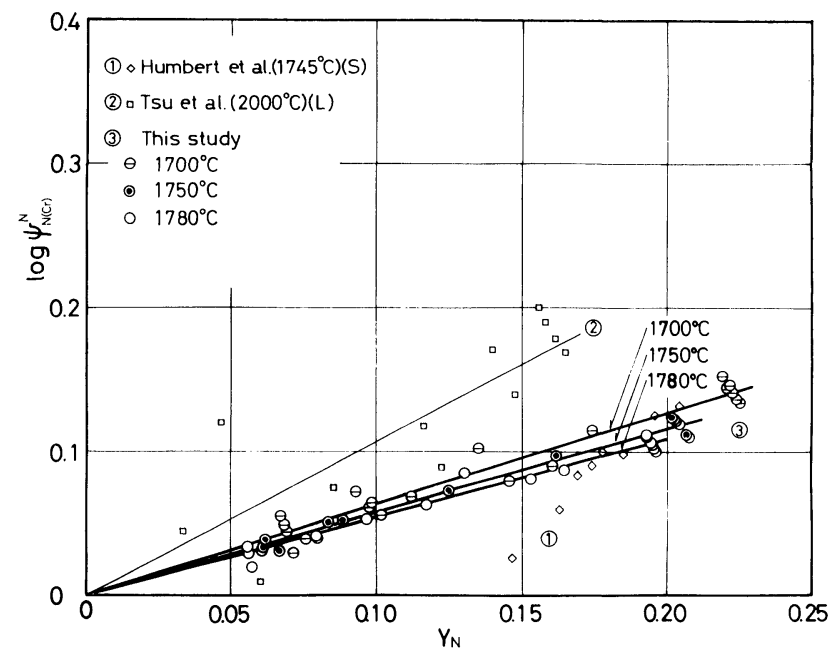

Fig. 5. Activity coefficient of nitrogen $\log \psi_{N(\mathrm{Cr})}^{N}$ in liquid chromium. 


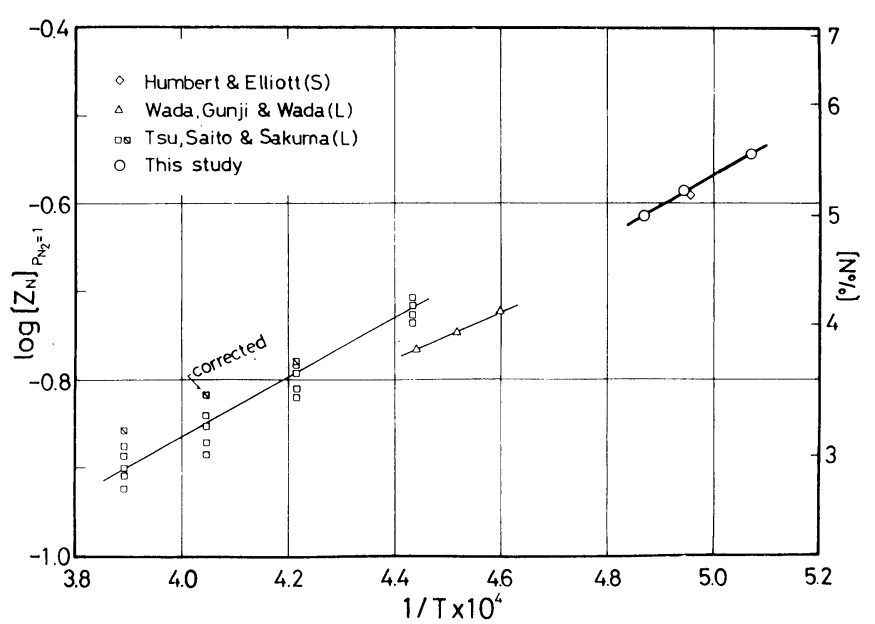

Fig. 6. Solubility of nitrogen in liquid chromium under $P_{\mathrm{N}_{2}}=1 \mathrm{~atm}$.

\section{Chromium-Iron System}

The solubility of nitrogen in liquid chromiumiron alloys was measured at the temperatures from 1550 to $1780{ }^{\circ} \mathrm{C}$. Figure 7 shows the results which indicate that nitrogen actually does follow the Sieverts' law up to $50 \mathrm{wt} \% \mathrm{Cr}$ in the liquid alloys. The infinitely dilute solution of nitrogen in pure chromium is taken as the reference state, and thus, the activity coefficient of nitrogen $\psi_{\mathrm{N}(\mathrm{Cr})}^{\mathrm{Fe}}$ in chromium-iron alloys is obtained by the following equation.

$$
\begin{aligned}
\log \phi_{\mathrm{N}(\mathrm{Cr})=}^{\mathrm{re}}= & \log K(Z)-\log K^{\prime \prime}(Z)-\log \phi_{\mathrm{N}(\mathrm{Cr})}^{\mathrm{N}} \\
= & \log K(Z)-\log K^{\prime \prime}(Z) \\
& -\left(\theta_{\mathrm{N}(\mathrm{Cr})}^{\mathrm{N}} / 2.303\right) \cdot Y_{\mathrm{N}} \ldots \ldots \ldots \ldots \ldots \ldots \ldots
\end{aligned}
$$

where, $K^{\prime \prime}(Z)$ : the apparent equilibrium constant used for the lattice ratio $Z_{\mathrm{N}}$ as the concentration of nitrogen in liquid chromium-iron alloys.

Figure 8 shows the effect of iron on the activity coefficient of nitrogen in liquid chromium. The results are somewhat scattered, but they all include the experiments shown in Fig. 7. The slope is the interaction parameter, and is represented as follows from 1650 to $1780^{\circ} \mathrm{C}$.

$$
\begin{array}{r}
\theta_{\mathrm{N}(\mathrm{Cr})}^{\mathrm{Fe}} / 2.303=\partial \log \phi_{\mathrm{N}(\mathrm{Cr})} / \partial Y_{\mathrm{Fe}}=1.80 \\
Y_{\mathrm{Fe}}<0.7 \sim 0.8 \quad \ldots \ldots \ldots . . . \\
\varepsilon_{\mathrm{N}(\mathrm{Cr})}^{\mathrm{Fe}} / 2.303=\partial \log \gamma_{\mathrm{N}(\mathrm{Cr})} / \partial X_{\mathrm{Fe}}=1.80 \\
e_{\mathrm{N}(\mathrm{Cr})}^{\mathrm{Fe}}=\partial \log f_{\mathrm{N}(\mathrm{Cr})} / \partial[\% \mathrm{Fe}]=0.017 .
\end{array}
$$

In Fig. 8, it is considered that the values of $\log \psi_{\mathrm{N}(\mathrm{Cr})}^{\mathrm{ri}}$ vary with the temperature in the higher range than $Y_{\mathrm{Fe}} \fallingdotseq 0.7$. Accordingly, in order to know this relation, the interaction parameter $\theta_{\mathrm{N}(\mathrm{re})}^{\mathrm{Cr}}$ based on pure liquid iron was calculated by using Eq. (24), which was the equilibrium constant with regard to the nitrogen solubility of pure liquid iron obtained by our previous work. $^{5)}$ The lines at $Y_{\mathrm{Fe}}>0.7$ in Fig. 8 were calculated by using Eq. (25).

$$
\log K_{\mathrm{He}}(\%)=-518 / T-1.06_{3}
$$

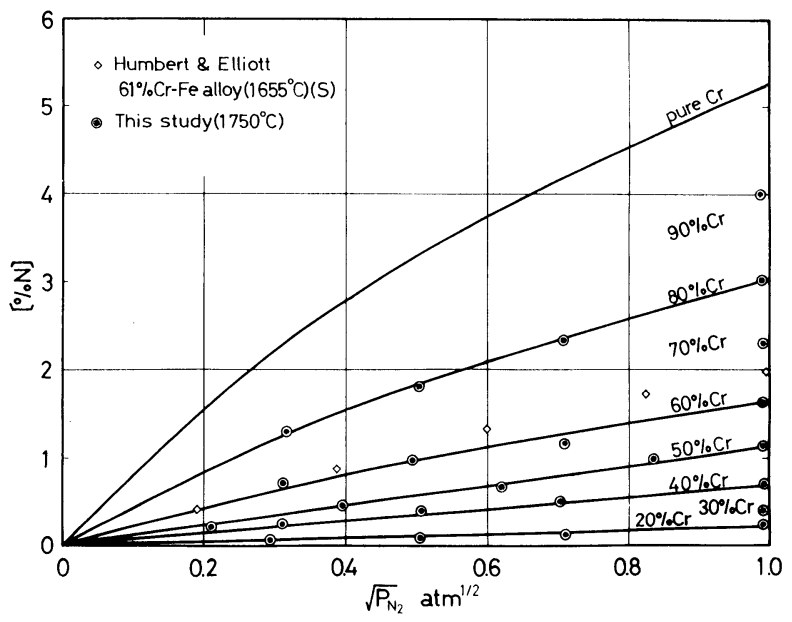

lïg. 7. Solubility of nitrogen in liquid chromium-iron alloys.

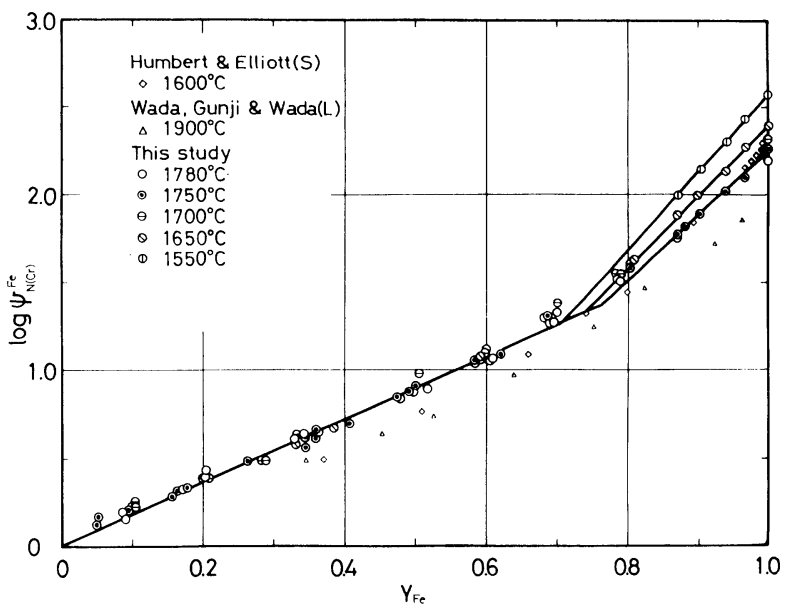

Fig. 8. Effect of iron on the activity coefficient of nitrogen in liquid chromium.

$$
\begin{array}{r}
\theta_{\mathrm{N}(\mathrm{re})}^{\mathrm{ir}} / 2.303=\partial \log \psi_{\mathrm{N}(\mathrm{ee})} / \partial Y_{\mathrm{Cr}}=-13440 / T+2.91 \\
Y_{\mathrm{Cr}_{\mathrm{r}}}<0.2 \sim 0.3 \quad \ldots \ldots \ldots \ldots \ldots \ldots . .(25)
\end{array}
$$

The values of $\log \phi_{\mathrm{N}(\mathrm{Cr})}^{\mathrm{Fe}}$ reported by earlier researchers ${ }^{1-3}$ ) are in fair agreement with the present results. As shown in Fig. 8, the application of the interstitial model to $\mathrm{Cr}-\mathrm{N}$ and $\mathrm{Cr}-\mathrm{Fe}-\mathrm{N}$ systems is useful to express the experimental results with the mathematical equations.

\section{Iron-Chromium System}

The effect of chromium on the activity coefficient of nitrogen in liquid iron has been measured by many investigators $^{1,7-16)}$ including the present authors. ${ }^{17}$ ) The solubility of nitrogen in pure liquid iron is $0.045 \mathrm{wt} \%$ at $1600{ }^{\circ} \mathrm{G}$ under one atmospheric pressure of nitrogen. ${ }^{5)}$ The application of the interstitial model to the experimental results is meaningless because of the simple relation of $Z_{\mathrm{N}}=Y_{\mathrm{N}}=X_{\mathrm{N}}=0.04$ $[\% \mathrm{~N}]$ in the range of low concentration of nitrogen in metal. Therefore, the activity coefficients of nitrogen in iron rich side were calculated by using $\mathrm{wt} \%$ nitrogen as a concentration variable. The results obtained are shown in Fig. 9. The interaction coefficient, $e_{\mathrm{N}(\mathrm{Fo})}^{\mathrm{Cr}}$, is -0.046 up to $15 \mathrm{wt} \% \mathrm{Cr}$ at 


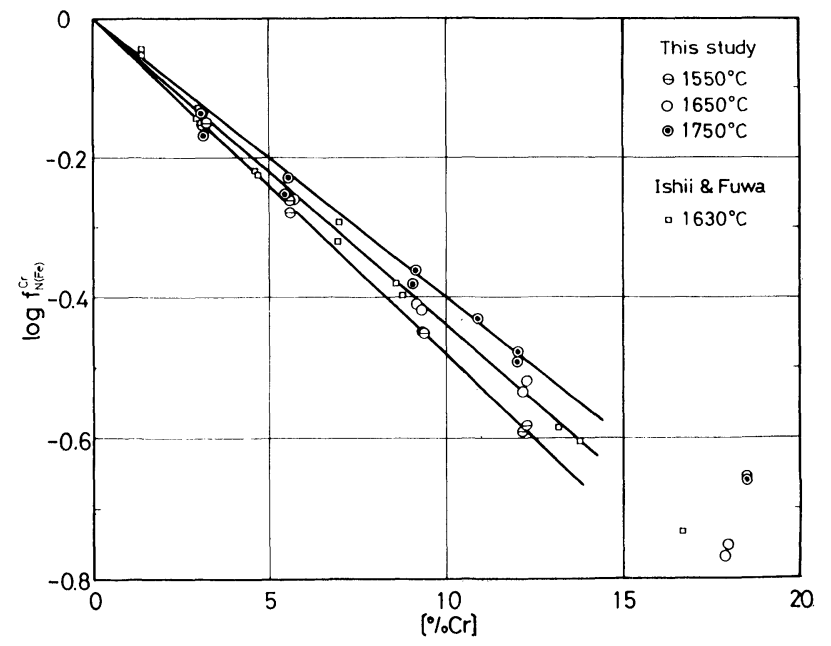

Fig. 9. Effect of chromium on the activity coefficient of nitrogen in liquid iron.

$1600^{\circ} \mathrm{C}$, and the present results may be expressed by the following equations.

$$
\begin{aligned}
& e_{\mathrm{N}\left(\mathrm{Fe}^{\mathrm{e}}\right)}^{\mathrm{Cr}}=\partial \log f_{\mathrm{N}\left(\mathrm{Fe}^{\mathrm{e}}\right)} / \partial[\% \mathrm{Cr}]=-148 / \mathcal{T}+0.033 \\
& \% \mathrm{Cr}<15 \\
& \varepsilon_{\mathrm{N}(\mathrm{Fe})}^{\mathrm{ir}}=\partial \ln \gamma_{\mathrm{N}(\mathrm{re})} / \partial X_{\mathrm{Cr}}=-31700 / T+7.14 \\
& X_{\text {(rr }}<0.15
\end{aligned}
$$

'The values of Eq. (26) consist with the interaction parameters converted from Eq. (25).

Figure 10 shows the influence of temperature on the interaction coefficients in liquid iron. These results agree well with the values obtained by Wada and Pehlke. ${ }^{16)}$ At the higher range than $15 \mathrm{wt} \% \mathrm{Cr}$, the values of $\log f_{\mathrm{N}(\mathrm{Fe})}^{\mathrm{Cr}}$ can be expressed by Eq. (28).

$$
\begin{aligned}
\log f_{\mathrm{N}(\mathrm{re})}^{\mathrm{Cr}}= & (-148 / T+0.033)[\% \mathrm{Cr}] \\
+ & (1.56 / T-0.00053)[\% \mathrm{Cr}]^{2} \\
& 15<\% \mathrm{Cr}<60 \ldots \ldots \ldots \ldots . .
\end{aligned}
$$

\section{Conclusion}

The solubility of nitrogen in liquid chromium and chromium-iron alloys was studied by the sampling method over the wide ranges of temperatures and pressures of nitrogen. The following results were obtained by applying the interstitial model to the experimental results.

(1) Nitrogen dissolution in liquid pure chromium and chromium-iron alloys up to $50 \mathrm{wt} \% \mathrm{Fe}$ does not obey the Sieverts' law.

(2) The solubility of nitrogen in liquid chromium is given by the following equation

$$
\log K(Z)=5515 / T-3.19_{3}
$$

(3) The activity coefficients of nitrogen based on liquid pure chromium are expressed as follows:

$$
\begin{aligned}
& \log \psi_{\mathrm{N}(\mathrm{Cr})}^{\mathrm{N}}=\left(4235 / T-1.51_{3}\right) \cdot Y_{\mathrm{N}} \quad Y_{\mathrm{N}}<0.21 \\
& \log \phi_{\mathrm{N}(\mathrm{Cr})}^{\mathrm{Fe}}=1.80 \cdot Y_{\mathrm{Fe}} \quad Y_{\mathrm{Ye}}<0.7 \sim 0.8
\end{aligned}
$$

(4) The activity coefficients of nitrogen in ironchromium alloys based on liquid pure iron are shown

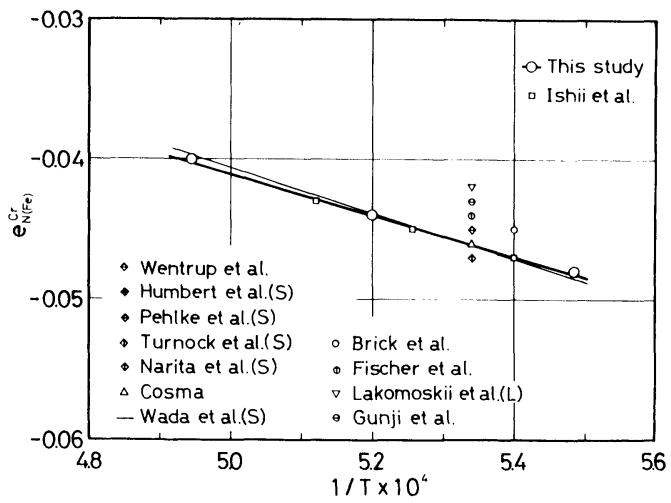

Fig. 10. Temperature dependence of interaction parame$\operatorname{ter} e_{\mathrm{N}(\mathrm{Fr})}^{\mathrm{Cr}}$.

by the following equations:

$$
\begin{aligned}
\log \gamma_{\mathrm{N}(\mathrm{Fe})}^{\mathrm{Cr}}= & (-13765 / T+3.10) \cdot X_{\mathrm{Cr}} \quad X_{\mathrm{Cr}}<0.16 \\
\log f_{\mathrm{N}(\mathrm{Fe})}^{\mathrm{Cr}}= & (-148 / T+0.033) \cdot[\% \mathrm{Cr}] \quad \% \mathrm{Cr}<15 \\
\log f_{\mathrm{N}(\mathrm{Fe})}^{\mathrm{Cr}}= & (-148 / T+0.033) \cdot[\% \mathrm{Cr}] \\
& +(1.56 / T-0.00053) \cdot[\% \mathrm{Cr}]^{2} \\
& \quad 15<\% \mathrm{Cr}<60
\end{aligned}
$$

\section{Acknowledgements}

The authors wish to thank Dr. Tasuku Fuwa, Professor Emeritus of Tohoku University. The authors are also thankful to Dr. T. Nagasaka and Mr. T. Oda for their assistance in the experiment.

\section{REFERENCES}

1) J. C. Humbert and J. F. Elliott: Trans. Met. Soc. AIME, 218 (1960), 1076.

2) Y. Tsu, T. Saito and K. Sakuma: Trans. JIM, 43 (1979), 71.

3) M. Wada, K. Gunji and T. Wada: Trans. ISIJ, 8 (1968), 323.

4) J. Chipman: Trans. Mel. Soc. AIME, 239 (1967), 1336.

5) F. Ishii, S. Ban-ya and T. Fuwa: Tetsu-to-Hagané, 68 (1982), 946.

6) S. Ban-ya, J. F. Elliott and J. Chipman: Trans. Met. Soc. AIME, 245 (1969), 1199.

7) R. M. Brick and J. A. Creevy: Metals Tech., Tech. Pub. No. 1165, (1940).

8) H. Wentrup and O. Reif: Arch. Eisenhüttenw., 20 (1949), 359.

9) R. D. Pehlke and J. F. Elliott: Trans. Mel. Soc. AIME, 218 (1960), 1088.

10) P. H. Turnock and R. D. Pehlke: Trans. Mel. Soc. AIME, 236 (1966), 1540.

11) K. Narita and T. Makino: Report of Cent. Res. Labs., Kobe Steel Works, Rep. No. 2087, (1968).

12) D. Cosma: Arch. Eisenhüttenze., 41 (1970), 195.

13) W. A. Fischer, M. Frye, M.J. Fleicher and R. Baum: Arch. Eisenhüttenw., 43 (1972), 291.

14) V. I. Lakomskii, G. M. Grigorenko, G. F. Trokhov and $\mathrm{Yu}$ M. Pomarin: The 3rd Japan-USSR Joint Sym. on Phy. Cihem. of Met. Processes, ISIJ, Tokyo, (1971), 72.

15) K. Gunji, K. Sudo and E. Ishikawa: The 4th JapanUSSR Joint Sym. on Phy. Chem. of Met. Processes, ISIJ, Tokyo, (1973), 185.

16) H. Wada and R. D. Pehlke: Met. Trans., 8B (1977), 443.

17) F. Ishii and T. Fuwa: Telsu-lo-Hagané, 68 (1982), 1551. 